European journal of American studies

\title{
Livin' Da Dream? Playing Black, Illusions of Meritocracy, and Narrative Constraints in Sports Video Game Story Modes
}

Michael Fuchs

\section{OpenEdition}

\section{Journals}

Electronic version

URL: https://journals.openedition.org/ejas/17368

DOI: 10.4000/ejas.17368

ISSN: 1991-9336

Publisher

European Association for American Studies

Electronic reference

Michael Fuchs, "Livin' Da Dream? Playing Black, Illusions of Meritocracy, and Narrative Constraints in Sports Video Game Story Modes", European journal of American studies [Online], 16-3 | 2021, Online since 10 September 2021, connection on 17 September 2021. URL: http://journals.openedition.org/ ejas/17368 ; DOI: https://doi.org/10.4000/ejas.17368

This text was automatically generated on 17 September 2021

Creative Commons License 


\title{
Livin' Da Dream? Playing Black, Illusions of Meritocracy, and Narrative Constraints in Sports Video Game Story Modes
}

\author{
Michael Fuchs
}

1 In his Polygon review of the best video games of 2017, Owen S. Good opines that "storydriven sports video games" defined the year. Narrative-centered career modes, he explains, "became a baseline expectation of the big-budget, league-licensed sport title, the same way every multiplayer shooter still has to launch with a campaign." While these story-driven career modes proliferated in the mid-2010s, modes featuring roleplaying-game-like elements had been a staple of sports video games before the introduction of story modes: Superstar, Be a Pro, My Player, and their ilk allow players to create their virtual stand-ins, develop and fine-tune skills, and-at the end of the day -succeed in the sport of their choice. Before the Web 2.0 era, players shared their stories on discussion forums and dedicated websites; today, the stories of players' virtual doubles are relayed through YouTube, Twitch, and similar platforms. By implementing career modes that use cinematic storytelling, big-budget sports video game franchises responded to the players' apparent need to "storify" their career experiences. Yet whereas paratextual career storytelling relies on the player's imagination and creativity, career story modes tell prefabricated stories.

2 These prefabricated narratives tap into one of the most durable and persistent American myths, the American Dream and the attendant success myth. The American Dream erases the social and material realities that living in the United States entails and the systemic obstacles marginalized groups face when trying to turn the myth into reality. Nevertheless, popular media have continued to reinforce and perpetuate the Dream. In this context, sports functions as a utopian space. Indeed, as Aaron Baker emphasizes in his book on sports in American film, a naïve belief undergirds the discourse on sports-that "once the contest begins, success depends primarily on one's 
determination and effort" (11). As a result, racism does not (seem to) exist in the world of sports.

3 However, "[r]ace and racism are central to sporting culture" (Leonard, Playing 3). From the Negro Leagues in baseball and the National Basketball Association's racially charged dress code of the noughties (McDonald and Toglia) to the "Kong LeBron" Vogue cover (Fuchs and Phillips 73-74) and Colin Kaepernick's protests against racial oppression and police violence (Boykoff and Carrington), sports and racial politics are inseparable. In this article, I will move from real-world sports to the virtual domain and examine the sports video game story modes in Fight Night Champion (EA Canada, 2011), a boxing game, NBA 2 K16 (Visual Concepts, 2015), a basketball game, and the narrative that stretches across Madden NFL 18 (EA Tiburon, 2017) and Madden NFL 19 (EA Tiburon, 2018), EA Sports' annual football series. As Brendan Keogh stresses, "videogame experience [is] an embodied textuality where the synthesized embodied experience of audiovisual design, videogame hardware, and the player's physical body constitute the site of meaningful engagement with the videogame" (31; italics in original). Crucially, this experience is characterized by various interactions: "The game locates the player within a complex network of exchanges, all mediated by technology: player-console/ computer, player-avatar, player-narrative" (Boulter 2). Here, I will focus on narrative and gameplay to show how these two dimensions coalesce into offering particular subject positions to players. I will suggest that the narrative straightjacket in these modes allows for barely any room for maneuvering, which reduces the players' illusion of control over their virtual athletes' careers.

4 Significantly, most of the virtual bodies players control in these games are black. The narrative constraints, then, come to symbolize the systemic obstacles African Americans (and African American athletes) still face in the United States, which the narratives, however, try to erase. White players such as myself thus become confronted with their "privileged place of racial normativity" (Newitz and Wray 3), as we (albeit only virtually) come to experience the limitations particular racialized subject positions entail. Ludically, white players perform digital blackface by subjugating black bodies to our control. However, as the games make us encounter narrative limitations and/or require us to virtually perform what Lisa Nakamura has called "familiar, solid, and reassuring versions of race" (40) that are decidedly not our own, the games acknowledge the constructedness of race and ask us not only to face up to our whiteness but also to concede "how technology is mobilized to fulfill the project of white masculine supremacy” (K. Gray 21).

\section{Quantifying Skills and the (Purportedly) Level Playing Fields of Sports}

5 The belief that those who work hard will earn financial and/or spiritual rewards has been a core American myth since the eighteenth century. "At its most basic," Julie Levinson has explained, "the success myth enshrines optimism and self-invention" (2). As such, this foundational American narrative downplays or even outright denies systemic limitations and social inequalities that keep individuals from realizing their versions of the American Dream. Although the American Dream "has inspired heroic individual success stories, ... it also has expressed itself in nightmares and human misery. As society continues to grapple with the reality of inequality, ... many have 
questioned whether [the American Dream] holds any sway over those who continue to face failure in its wake" (Cernkovich, Giordano, and Rudolph 131-32). Despite this erosion of the American Dream in view of social and material realities, popular media have continued to reinforce and perpetuate the myth of American success and its concomitant ideologies. In this context, sports has been celebrated as a postracial and meritocratic utopia disconnected from social, economic, and political realities.

On the level of the video game code, characteristics such as determination and effort as well as particular skills must be converted into sequences of 0 s and 1s. While there would be a variety of ways to transform these numbers into more abstract shape in the graphical user interface, sports video games (similar to digital role-playing games) have largely embraced quantifiable ratings systems, which generally cap at 99 or 100 points (Illustration 1). As Nicholas Ware has explained, "These ratings allow gamers ... access to a seemingly-objective ranking system of players' skills," as this rating system is based on "the illusion of a fair, quantifiable, meritocratic assessment of player skills" (88).

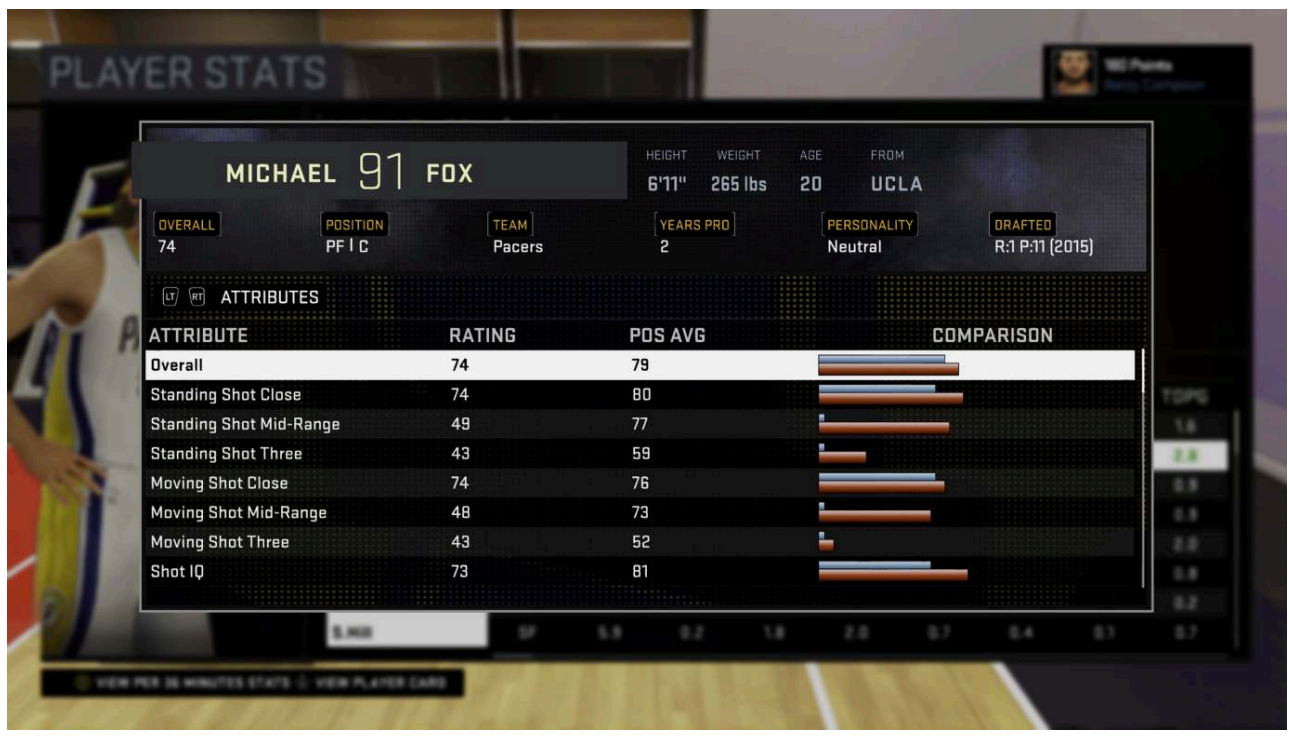

Illustration 1: Skills are translated into numbers. Screenshot from NBA 2 K16 $\odot 2 \mathrm{~K}$ Games, 2015.

7 Notably, the online magazine Quartz has found that the ratings of soccer players in Football Manager 2019 (Sports Interactive, 2019) harbor racist biases: "[P]layers and staff with darker skin tend to have worse ratings on non-physical attributes" (Kopf). These findings point at stereotyping in sports on a more general level. For example, according to a study on stereotyping in men's college basketball, the success of white players is usually attributed to "hard work, leadership ability, access to better coaching, and access to better equipment and facilities," while African Americans' success is primarily believed to be due to "innate athletic abilities" (Johnson, Hallinan, and Westerfield 45). This connection between black male bodies and "natural" physical abilities has a long history-the black male body provides access to animalistic wildness and physical prowess which white men left behind when evolution increased their intellectual capabilities. By tapping into the cultural repertoire of racialized representations of African Americans, video games, as David Leonard has noted, "legitimize stereotypical ideas about black athletic superiority and white intellectual abilities" ("Performing Blackness" 326). In addition, the purported objectivity conveyed by the numbers 
provides a pseudo-scientific rationale for racist differentiation among human beings, similar to how the pseudo-science of eugenics gained credibility in the latter half of the nineteenth century.

These implicit racisms are codified into the procedural logics of video games. As Gillian Smith has rightly stressed, procedural systems "can only interact on the basis of what they have been 'told' to understand." Indeed, Amiri Baraka concluded as early as 1971 that "[m]achines have the morality of their inventors" (157). Since stereotypical notions about particular groups of people are implemented on the level of sports video games' procedural logics, these ideas become even more pronounced when playing these games.

\section{Virtual Boxing and Narrative Imprisonment}

Fight Night Champion tells a rather clichéd story about an African American boxer reaching the top. This journey is characterized by overcoming obstacles, which are repeatedly represented or created by white people, and his need for support by white friends and associates. For a white player controlling the black boxer, the subject position of an athlete and the socioeconomic situation of being in need of white people's support cements beliefs and assumptions about raced bodies. While the narrative layer thus underscores the centrality of race to sports, the lack of control players enjoy over the career of their boxer exposes the restrictions African Americans face on an everyday basis and confronts white players with their privilege.

FNC was the last unlicensed EA Sports video game title and inaugurated the story-based career mode, featuring a script written by Hollywood veteran Will Rokos. ${ }^{1}$ FNC's story centers on African American boxer Andre Bishop and draws on a narrative template provided by sports movies. The narrative accordingly features all of the melodrama and pathos characteristic of the genre-the protagonist overcomes a variety of obstacles on his way to the top, the idealized meritocratic world of sports is contaminated by illegal outside interference, an interracial romance sub-plot unfolds (whose consummation is only hinted at, thereby containing the threat of black male sexuality), and the narrative concludes on an uplifting note. Due to their "nostalgic, and melodramatic narratives, which tend to flatten out complexity in favor of uplifting sports stories with "universal appeal," sports films "are thought to be formally banal, filled with clichés about team work, discipline, and athletic achievement" (Sheppard 162). However, as Richard King and David Leonard have pointed out, "[s]port films are not just movies or fantasies regarding the world of sports, or even mere sites of racial or gendered stereotypes, but a medium replete with American discourses, ideologies, and racial dynamics" (229).

11 In FNC (and the other video game examples discussed below), these dynamics are interconnected with the ways in which narrative limits player choice at particular junctures. Indeed, while player choices are increasingly restricted, Andre gradually takes control over his life. This process becomes particularly evident in the last three bouts in FNC's career mode. FNC uses a fighting system which depends on the player using the thumb sticks to throw punches at the opponent and the trigger buttons for blocking and evading. Throwing punches has an impact on Andre's stamina and balance; hitting the opponent affects the opponent's stamina, balance, and health. Each boxer uses a particular strategy and has specific strengths and weaknesses-players 
have to plan their strategy accordingly. Following some intrafamilial tensions, Andre steps into the ring with his younger brother Ray. No matter how well Andre/the player performs early on, after the first round, his coach complains, "What's going on, kid? You look like crap out there!" Andre decides that he does not have to win the boxing match against his brother. As round two starts, Andre's stamina quickly drops. Ray lands a few punches and Andre is down. Players cannot do anything to keep Andre's knockdown from happening-and neither can they get Andre back on his feet. Players are thus forced to accept that Ray wins and that the game relieved them of the decision as to whether to fight Ray or not. When Ray then faces off against $F N C$ 's rendition of the "white hope," Isaac Frost, players take control of Frost, who seems invulnerable and does not get tired; any of his punches, on the other hand, may knock out Ray. Indeed, as soon as one punch hits hard, Ray is severely injured. Thanks to the help of his manager, Megan McQueen, Andre gets a chance to fight Frost to avenge his brother and to compete for the title.

12 The championship fight between Andre and Frost unfolds in various stages: First, Andre needs to "survive the first 2 rounds" (Illustration 2); then, his coach tells Andre to "knock the air out of [Frost's] lungs [for] three rounds," which is translated into landing at least seventy-five body blows over the next three rounds; however, a cut opens above Andre's right eye in round five. Andre needs to protect this wound in order for the referee not to step in and rule the fight a technical KO in Frost's favor. Andre hence has to keep Frost from scoring more than seven hits to his head each in rounds six and seven. In round number eight, Andre goes on the offensive, as Frost "spent a lot of energy" in the previous rounds. In very anticlimactic fashion (in terms of ludic fulfilment after reaching that point; however, the scene is staged like a Hollywood movie), Frost goes down after a handful of hits.

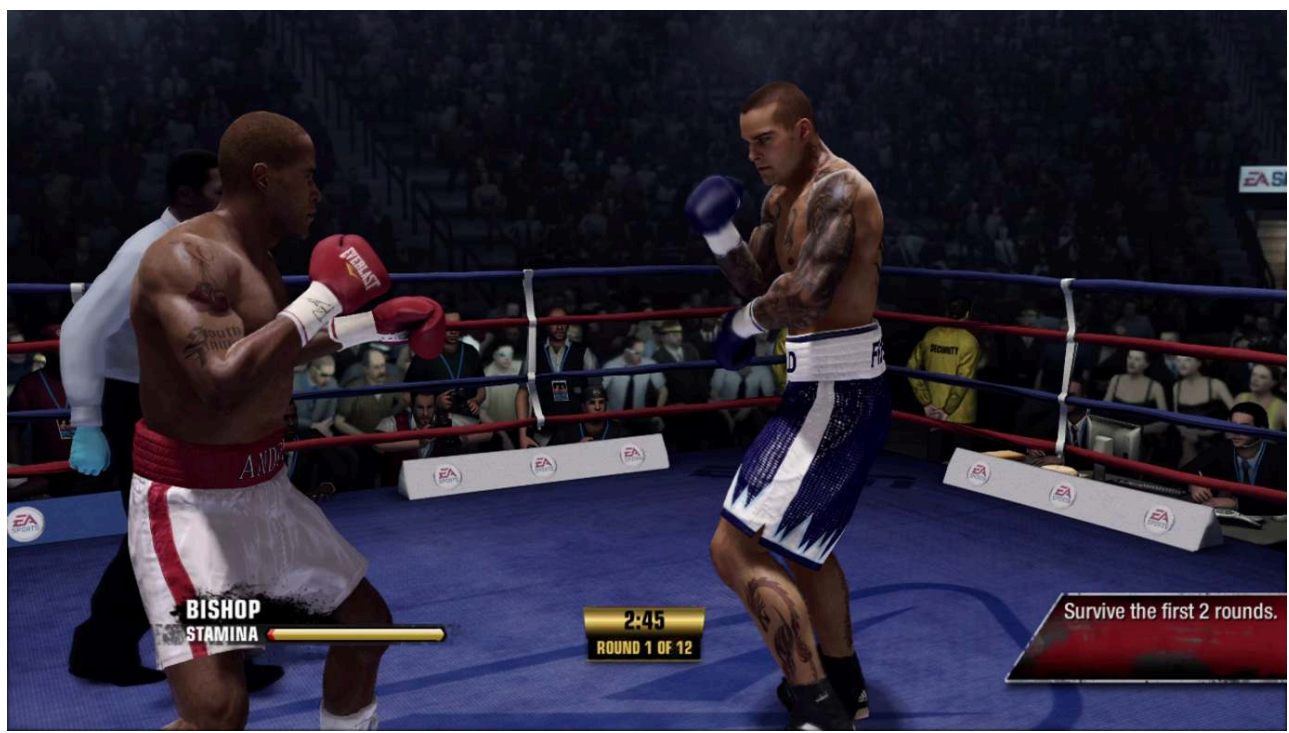

Illustration 2: Andre needs to make it through the first two rounds. Screenshot from Fight Night Champion (๑) EA Sports, 2011.

13 In the latter stages of the story mode, FNC deploys gameplay in the service of narrative. As Malte Elson, Johannes Breuer, James D. Ivory, and Thorsten Quandt have explained, video game experiences "are not only elicited by narrative and audiovisual presentation"; crucially, "interactivity adds a whole new layer of user experiences affecting both hedonic and eudaimonic gratifications in ways that are unique to the 
digital game medium" (524). However, toward the end of the story mode, gameplay becomes frustrating. As the review by the user ScareCrow on Metacritic states: "[E]ven as a very skilled player I was frustrated with the final boss battle-essentially your ability to choose how to fight is completely taken away and you must 'do exactly what the game says' and not play the game as a sentient being capable of making your own decisions."

The resultant lack of ludic control over the fights on the player's part is at odds with Andre's increasing confidence and pride on the narrative level. As Xalavier Nelson remarks in a recent essay on FNC, "[W]hen Andre Bishop sinks his fist into another Nazi face, or gets the championship belt he earned against every odd and disadvantage, I feel a sense of freedom myself. He unleashes himself, and grins, and screams his greatness and joy to the world. He doesn't have to apologize for existing anymore." This interpretation embraces Andre's overcoming of obstacles and transcending of his social background and showcases one way in which players might respond to the video game; however, Andre's rise is rooted in white people's victimization of Andre and Megan's emergence as a white savior. After all, the events which truly shape and then transform Andre's life (that is, the parts that players get to witness) are getting doublecrossed by Megan's father, promoter DL McQueen, Andre's repeated confrontations with skinheads while serving a prison sentence, and Megan convincing him to restart his career. McQueen frames Andre because the African American repeatedly declines the promoter's offers, which require Andre to replace his longtime trainer and mentor Gus. Accordingly, Andre becomes a beacon of humanist idealism and epitomizes interpersonal loyalty (Gus was his dad's trainer, as well) in the hypercapitalist world of sports. However, this idealism and the attendant belief in the goodness of people land Andre in jail.

The bouts with white supremacists in prison render the racial subtext most explicit, as the tensions between white and black Americans are acted out in the boxing ring. Notably, the story mode starts with these fights in prison. After beating one of the white supremacists in the ring, Andre is beaten down in the showers. This beatdown triggers a flashback, which segues into a workout montage that eventually takes the story to Andre's amateur boxing days, before the narrative returns to Andre's prison sentence some years later, as Andre beats a few more neo-Nazis. This narrative structure suggests that Andre's victimization unleashes his recalcitrant self.

Even though Andre stresses that he "had to help" himself, Megan is, in fact, the one who saves him from "clean[ing] ... toilets" for the rest of his life. While Megan's support of Andre's (second) career testifies to their interpersonal relationship, she-as a white woman-uplifts Andre, as helping Andre advance his career seems to become her calling. Megan is a white savior, a "white messianic character" who "saves a lower- or working-class ... nonwhite character from a sad fate" (Hughey loc. 50). As Matthew Hughey has explained, the ideology underpinning white saviorism is problematic, as it "enables an interpretation of nonwhite characters and culture as essentially broken, marginalized, and pathological, while whites can emerge as messianic characters that easily fix the nonwhite pariah with their superior moral and mental abilities" (loc. 66). Herein lies FNC's progressive subtext, however. Andre is not "essentially broken." After all, Megan's father set up Andre because he was not willing to toss away a fight; Andre was immune to corruption. However, cultural assumptions about black men from a poor background as pathological made it easy to frame Andre. 


\section{Passing for Black and Narrative Inconsistency}

Whereas FNC struggles with racial representation and ludic control over black bodies, NBA 2 K16 takes a more radical route. The story mode presumes its protagonist to be African American while simultaneously inviting players to insert themselves into the game. Especially for white players, this narrative expectation creates a dissonance-not only on the narrative but also on the ludic level, as the game confronts them with their position of racial normativity.

When launching the game for the first time, a dialogue box directly addresses players after an opening cinematic:

Start off by creating your very own MyPLAYER!

This is an important part of your NBA 2K16 experience, as your MyPLAYER will represent you in places like MyCAREER, MyGM, MyPARK, 2K Pro-Am, and for the very first time, as the star in an original Spike Lee Joint.

Make sure to pick a name and likeness. You can go with a preset look or use your skills to sculpt yourself through our custom toolset.

No matter what you choose this year in NBA 2K16, YOU get to \#BeTheStory!

Players are taken to the MyPLAYER creation screen right after. In fact, if I accept the game's invitation and scan a recent photo of myself to create a virtual likeness, my MYPLAYER is a white, bearded guy with long brown hair (the 2015 version would have had a slightly different beard and a few pounds less). Of course, I may choose one of the preset looks, use a random photo to base my virtual likeness on, or customize a virtual athlete to my liking; however, the use of a white player exposes an important dimension of the game's racial politics, which prioritizes blackness over whiteness.

Upon selecting the career mode in the main menu, players are turned into viewers and transported behind the scenes of the story mode's production, as two African American actors and an African American actress are being recorded in motion capture suits. After a few seconds, Spike Lee screams, "Oh! Cut, Cut! Cut! Cut! Cut!" from the offscreen space. The camera turns toward him, and he addresses the player/viewer:

This year, NBA 2K16 will take a new approach to your MyCAREER story. Expand your world to something bigger and better than before. There's a lot more to being a great baller than what you see on the court: High school, college, choosing an agent, getting drafted, developing a personal brand, and family. The pressures of stardom are very real for you and everyone around you, but the rewards can be equally as powerful. If you're willing to put in the work. So, let me tell you a story.

This illocutionary act (that is, Spike Lee's promise to tell a story) triggers a cut, as a digital Spike Lee takes the stage (Illustration 3), who continues, "Step into MY world, where YOU can be the story. See what it's like to be the next NBA phenom. The next Frequency Vibrations, a.k.a. "Freq." When Spike says "next Frequency," a generic player model is replaced by the player's MyPLAYER (Illustration 3). Spike continues, "This is 'Livin' Da Dream." 

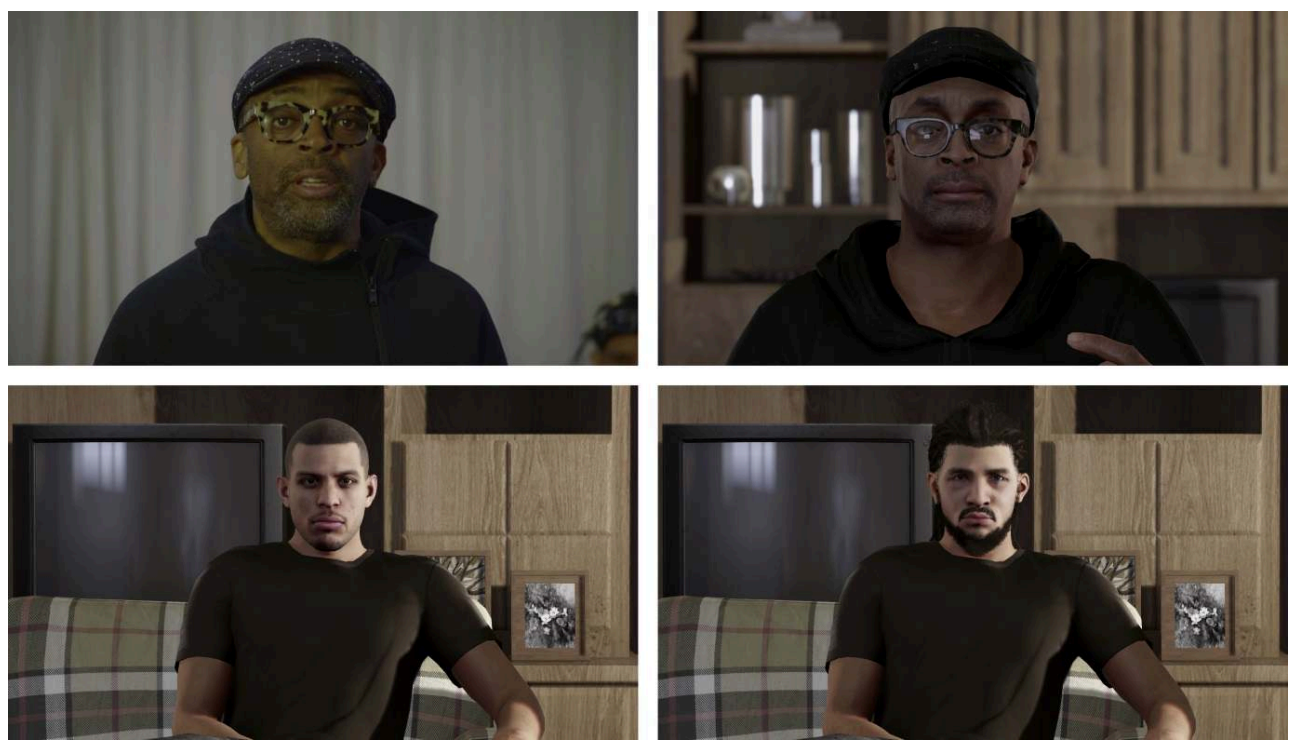

Illustration 3: Spike Lee is replaced by his virtual likeness and the generic player model by the MyPLAYER. Screenshots from NBA 2K16 @ 2K Games, 2015.

As Lee intimates, the narrative revolves around Freq, who grew up "in the projects" of Harlem. Freq is a basketball prodigy who receives offers from multiple top-notch college basketball programs. Similar to $F N C$, the career mode alternates between prerendered narrative scenes and basketball game simulations in which players control Freq. After three games of high school basketball, Freq chooses his future college. In a scene which recalls the myopic debacle that was The Decision (in which basketball superstar LeBron James turned his back on his hometown team), Freq announces his decision on social media. Whichever choice players make, after his freshman year, Freq enters the NBA draft. Freq's college performances have an impact on what NBA team selects him, but where Freq ends up playing has no effect on the story. In his first season in the NBA, Freq earns millions of dollars and develops his brand, but his connections to his childhood friend Vic, who constantly stresses that Freq needs to "recalibrate back to Harlem," become a burden. After his first season in the NBA, Freq signs with a new team. As Freq and his family are celebrating his new contract, the police inform them that Vic was killed in a car chase. Some time later, Freq and his twin sister return to their childhood neighborhood and the court where "it all started." Freq and his sister surprise their parents with a new home, and as they leave their childhood home behind, Vic's ghost enters the stage and delivers an eight-minute monolog that reflects on his life and how he did not fit in with Freq's rise to the top of the NBA. Following the live-action credits, the game transforms into a "regular" career mode-with games to play, endorsement deals to score, new contracts to sign, etc.-as the player-character's second year in the NBA starts.

TreaAndrea Russworm has written two illuminating pieces on NBA 2K16's career mode. In her contribution to How to Play Video Games (2019), she critiques "the ideological work [African American] characters facilitate, including how gamers feel about and express empathy for such characters" (126). Starting from this thesis, she explores players' reactions to Freq's best friend Vic and suggests that "truly empathic players might have felt sorrow with Vic as he delivered his painful revelation that he did not fit in with Freq's pursuit of the American Dream" (130). However, "the game's default blackness," she suggests, "undermines empathetic role-playing" (130). To be sure, Vic 
is not a character who is easy to empathize with. He is constantly in legal trouble, tries to cash in on his relationship with Freq wherever he goes, blackmails his purportedly best friend, and so on. More importantly, not the "game's default blackness" (my emphasis) produces a disconnect-the narrative mode's "default blackness" does. After all, the game invites players to create their digital likenesses through the implementation of face scanning technologies and the direct address "to sculpt yourself" in the opening dialog box, but upon entering the career mode, Spike Lee makes explicit that he tells his story-which the player (through the interface of the player-character) becomes part of. The opening dialog box promises players that they "get to \#BeTheStory!" However, they find themselves trapped in a prescribed (and prescripted) role in which none of the few decisions they make-or their virtual performances on the basketball court-really matter until they have reached the end of the story: "Sports video game 'create-a-player' modes are successful because they allow regular couch potatoes that cannot make it to the $b[i] g$ time in real life to live out their aspirations in the game," Metacritic user CanuckHoster notes and continues, "Spike Lee's overly scripted mode leaves NO room for freedom and very little room for personalization." Comments such as this showcase the "irresolvable tensions between ... gamic and cinematic elements" Russworm has diagnosed in the NBA 2K16 story mode (“Computational Blackness" 207).

To be sure, that Spike Lee tells an African American story is not surprising, as many of his films center on how "[t]he social structures of racism emerge and thrive through the passion of the subjects who sustain them" (McGowan 4). In addition, basketball is the black sport in the United States: Despite the recent influx of players from around the world, African Americans still account for close to seventy-five percent of NBA players (Tower), and the NBA is the only major North American sports league that does not have a white viewership majority-about half of the NBA viewers are African American, while only about a third are white (Piacenza). Hence, one could argue that the "default blackness" Russworm diagnoses pertains to the actual NBA as well.

If players create a MyPLAYER of an ethnicity other than African American, the career mode's "default blackness" produces a dissonance, which user reviews on sites such as Metacritic testify to: "Having to be twins with a black sister and being part of a black family as a white person will never make sense to me," user Schoonie30 complains, for example. While Schoonie30 emphasizes the narrative inconsistency, the "default blackness" simultaneously confronts players with white privilege. By focusing on an African American athlete and his family and refusing to offer white basketball players the chance to take center stage, NBA 2K16 exposes the systematic overrepresentation of white males in video games; it tries "to make whiteness strange" (Dyer 4).

User greedoinaspeedo echoes Schoonie30's critique, but adds an important dimension:

MyPlayer this year forces you to be a player named Frequency Vibrations from the projects in Brooklyn, and have an African American family with a twin sister. ... I'm trying to figure out how to reconcile these things as I hear the story and look at the Spaniard I have created to resemble myself. ... Spike Lee has made myplayer mode feel like it's choosing to exclude me, and make me feel that by participating I am appropriating a culture that is not mine.

Whereas Schoonie30's response may be a reaction to being confronted with white privilege and the attendant dominance of whiteness in the media, the Hispanic player's critique is more pronounced, as the narrative excludes nationalities other than American and marginalized ethnicities other than African American (and, of course, 
only allows players to control male athletes). In particular, being part of an African American family-a biological family-requires players to reconcile the narrative with decisions they made before the story mode even started. In addition, greedoinaspeedo's comments emphasize the odd, even uncomfortable, feeling of being effectively required to play black. After all, even if players may create a white Freq, he is coded black, from the family background to voice and speech.

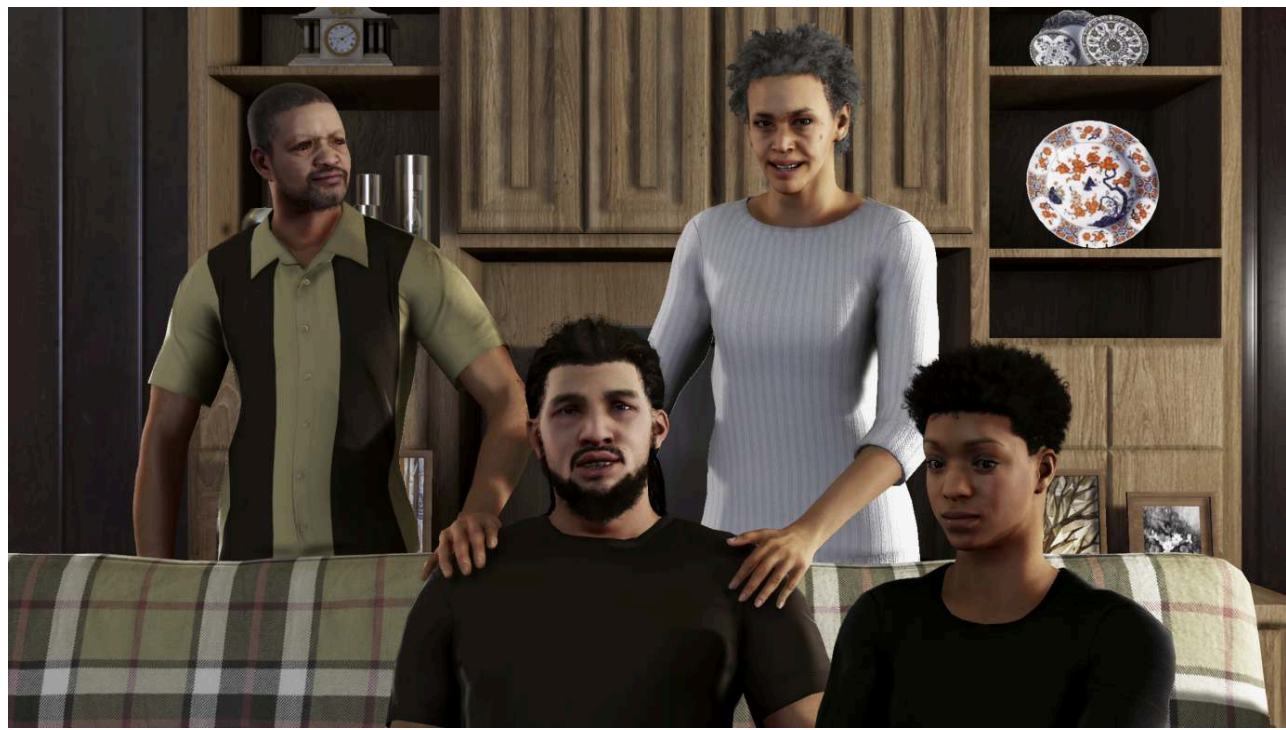

Illustration 4: Freq and his family, including his "fraternal twin sister." Screenshot from NBA 2K16 @ 2K Games, 2015.

When playing black as a white player, the unpleasant feeling described by greedoinaspeedo becomes exacerbated by the historical baggage of blackface and passing as black as forms of socially hierarchized and accepted cultural appropriation. Whites trying to pass for black, as Gail Ching-Liang Low has suggested, indulge in a paradoxical fantasy of becoming without becoming (188)-that is, they momentarily pretend to be black without having to face the lifelong racism and systemic oppression African Americans encounter. In addition, passing for black presupposes a hegemonic white subjectivity which can be anywhere at any time, further empowering said subject position through the "demarcating imperative" that seeks to systematically distinguish between colonizer and colonized (Stallybrass and White 191).

While this jump to the discourse of colonialism might seem jarring at first, the NBA's racial setup, in which primarily white CEOs and majority shareholders have control over black bodies, continues exploitative labor practices and structures. These historically charged hierarchies have repeatedly come to the fore in recent years. During the 2011 lockout season, for example, HBO's Bryant Gumbel referred to thenNBA commissioner David Stern as "some kind of modern plantation overseer" (quoted in Leonard and Hazelwood 122). More recently, HBO's The Shop caused quite some waves after discussants addressed the question of ownership in the talk show's premiere. In the episode, Golden State Warriors forward Draymond Green opined, "You shouldn't say 'owner," as terms such as CEO, chair(wo)man, and majority shareholder are less loaded. In the episode, Jon Stewart (the comedian and television host) explained, "When your product is purely the labor of people, then 'owner' sounds like something that is of a feudal nature." A few months later, NBA commissioner David Silver highlighted in an interview with TMZ that the league "moved away from that 
term ['owner'] years ago," which provided fodder for FOX and similar "conservative" outfits to condemn the "PC police." Tucker Carlson, for example, sardonically noted, "NBA players, some of the richest people in America, now are finding out that they're actually oppressed by the term 'owner"' (Creitz). Carlson's downplaying of the gravity of the issue consciously ignores that despite individual successes, "African American athletes ... still find themselves on the periphery of true power in the industry their talent built" (Rhoden, Forty Million 2).

Tellingly, the unnamed owner of Freq's team in NBA 2K16 is a white man-and he never fails to stress that he owns the team and, implicitly, the players. At the same time, he acknowledges Freq's value to the team; ${ }^{2}$ to his disapproval, Vic and Freq do not play by the team owner's rules:

I respect, admire, and-most importantly-love you as a human being and a role model. But I pay you a lot. ... The only thing that Vic brings into your life is headache and unwanted and unnecessary negative attention, and it will begin to affect your mindset. And when it affects your mindset, it's going to affect your play. And when it affects your play, it's going to affect my team. And when it affects my team, it's going to affect my money! ... Handle your business. And remember that contract you signed contains a morality clause.

31 First, even though the team owner initially stresses that he appreciates Freq as a human being, the lengthy tirade demonstrates that the owner views his player as an investment that he expects to yield a return in the not-too-distant future. Second, the morality clause evokes the "practice of policing young Black males who defy dominant expectations" (Leonard, "Real Color" 160), which reveals that white America is still afraid of the black male body. Popular narratives which center on the need to control African American bodies "presume and then fix in representation the purported natural affinity between black criminality and threats to the nation" (H. Gray 25).

While Freq initially defends Vic, he becomes increasingly agitated by his friend's antics. Vic's eventual death signposts Freq's acceptance of his place in the racially hierarchized system of the NBA. With Vic dead and his parents set to leave Harlem, Freq's origins are erased. Freq sheds his links to "the hood" (as the team owner dismissively calls it) as he moves from the bottom of the social ladder to the top. Vic represents a link to the past, a connection to the authenticity of Freq's life prior to the NBA, and Vic's ties to their childhood neighborhood symbolize class (and race) solidarity. But when Vic dies and Freq decides to move his parents away from Harlem, these ties to the past and the community are severed. As early as the early 1990s, Paul Silas, sixteen-year NBA veteran and then-assistant coach of the New Jersey Nets, highlighted the disconnect between star athletes and their working-class roots: "They're in a quandary because they don't really fit anywhere. They want to belong; they don't want to change because they want to be like their 'bros.' But they're not. But they don't fit in that other echelon, either, in white society" (quoted in Rhoden, "Challenging").

In NBA 2K16, the team owner may emphasize that trying to keep Freq at a safe distance from Vic "isn't about class warfare," but his measure reveals the intersections between the race and class struggle. Vic represents Freq's past self, which does not fit in with Freq's pursuit of the American Dream and which must be buried in order for Freq to realize his dream. Indeed, Freq fulfils his dream of becoming an NBA star, but the narrative's conclusion, which focuses on individual success and pursuing one's dream, overshadows the social concerns and systemic issues that the story at times hints at. 


\section{Biracial Buddies and Multicultural America}

Madden NFL's "Longshot" story offers a different take on some of the issues explored above, as it taps into ethnic stereotypes while celebrating meritocracy in (purportedly) postracial America. However, the narrative also opens up alternatives to financial success while the "inversed" racial hierarchy it embraces in its final chapters imagines the possibility of overcoming ethnicity-based hierarchies through personal connections.

"Longshot" focuses on childhood friends Devin Wade, an African American, and Colt Cruise, a white boy, who grew up in rural Texas and played college football for the Texas Longhorns. Devin emerged as the team's star but imploded in a game against the Oregon Ducks shortly after his dad died in a car crash, which led to him abandoning the team. Devin's story-from high school sensation to college "quitter" who ends up joining the US Army in Afghanistan, where he rediscovers his love for football-and his performance at the NFL Combine attract the creators of a television show that pits four quarterback "hopefuls" against one another and follows them to the NFL draft. The very presence of the television show within the video game helps underscore the mass mediatization of sports (in which, of course, NFL Madden also plays its part), which is at odds with Devin's seemingly naïve understanding of sports and his innocent belief that the best athletes will emerge victorious. Colt, in contrast, views the television show as a chance to showcase Dev's talent, rewrite Dev's story, and, in the end, land a big contract. Colt is the business-savvy, solution-oriented, and street-smart white friend who provides the supervision, guardianship, and care that the black athlete needs.

Although Dev wins the nationally televised contest, the draft concludes in one of three ways (depending on various choices in the course of the story mode and performances on the field), none of which sees Dev being drafted before round six. Madden 19 establishes a timeline in which both Colt and Devin initially made it into the NFL. Both were quickly released, but Devin is picked up by the Dallas Cowboys before training camp starts. The story's focus then increasingly moves from the football field to the personal drama Colt experiences in their childhood home of Mathis, where he begins to coach their high school team, the Bullfrogs, who face financial hardship. With Colt at the helm, the team's fortunes turn on the field, but the Frogs are still in need of funds. At a fundraiser, Devin's NFL teammates step up to the plate and generate the money needed to secure the Bullfrogs' survival. In the end, both friends have made it in their own ways-Devin's star begins to rise in the NFL, while Colt is happy in Mathis.

In terms of racial stereotyping, one element that "Longshot" repeatedly focuses on is Devin's lack of intelligence-an inability to grasp even the simplest of plays in the playbook, an inability to memorize play calls, and an inability to read plays as they unfold on the field. When Devin prepares for the NBA draft, his coach thus decides to "simplif[y] everything for him." But even so, Devin may "take all night" to learn the playbook. Similarly, in the early stages of Madden 19, Devin cannot remember the play the coach tasked him to call. The game thus supports the very troublesome view of African American athletes as intellectually inferior to whites.

The "blatantly racist stereotype of the "dumb Negro"' (Harry Edwards in Hawkins 65) may, of course, be traced back to colonial times. In the NFL context, it has been particularly prevalent in relation to black quarterback prospects such as Devin. 
Whereas the majority of football players are African American, quarterbacks are still overwhelmingly white. At the NFL Combine, players take the antiquated Wonderlic test, which assesses players' cognitive abilities based on their answers to fifty questions that they have to complete within twelve minutes. For example, when (African American) Cam Newton scored a 21 (out of 50) on the test prior to the $2011 \mathrm{draft}$, people were wondering whether he had the intelligence required to play quarterback in the NFL, as a score of 20 is generally considered the baseline for the position. These discussions have continued throughout his career. After Newton had earned the 2015 NFL Most Valuable Player, a football fan remarked that winning the award "really says a lot for his physical gifts that he can overcome such a disadvantage. ... what an athlete. almost superhuman. yet underneath the bravado, borderline retarded with a juvenile attitude that involuntarily comes with an underdeveloped brain" (flowsion). This statement recalls racist ideas such as Lewis Terman's infamous claim that "[n]o amount of school instruction will ever make [African Americans] intelligent voters or capable citizens" because "their dullness seems to be racial" (91). In addition, the racist description of Newton's lack of intelligence and childishness demonstrates the pervasiveness of these African American stereotypes in cultural practice and makes explicit that sports is far from postracial; sports and the discourses surrounding sports reinforce "race-relevant cultural and structural realities in people's minds" (Plaut 84). ${ }^{3}$

The narrative's focus on Devin and Colt's biracial friendship seems to imagine a colorblind world, but this friendship is trapped in racially coded binaries. Notably, the two characters repeatedly need one another-whereas Colt helps Devin thanks to his business-savvy, Devin's loyalty to his hometown and his white friend bears the imprint of the loyal (and frequently rather simple) African American sidekick. "Longshot" slightly deviates from the buddy movie's generic script, though. Although Colt is more determined to make it in the NFL, he relatively quickly comes to understand that he can have a successful and fulfilling life in Mathis. Devin, on the other hand, is ready to abandon the idea of becoming a professional football player early on, but as the story comes to a conclusion, he is about to rise to superstardom in the NFL. Indeed, Devin's characterization taps into long-established stereotypes of African Americans other than their intellectual inferiority. First, he is guided by his emotions and thus becomes frustrated quickly, which nearly ends his career. In addition, he seems to be a "natural" who does not need to put much of an effort into being an outstanding player. However, in contrast to NBA 2K16's Freq, Devin stays in his home state and does not sever his links to his working-class background-and he is willing to give back to his hometown community. While Freq is, in nearly typical fashion, "contained by ... [his] isolation from a black community" (Gates 21), living in a luxurious apartment, having a model as his girlfriend, and owning several expensive cars, Devin embraces his connection to his multicultural hometown of Mathis, which does not seem to know of structural and historical injustices. Indeed, there seems to be a kind of "unwritten, unspoken, felt understanding," to draw on Benjamin DeMott (11), between Devin, Colt, and the rest of the Mathis community-a sensibility that unites the town and which allows both Cold and Devin (but also their Hispanic friend Gabriel Romero, who is put in charge of building a new stadium in Mathis) to pursue their versions of the American Dream.

This emphasis on the variety of realizations of the American Dream is one dimension that renders the "Longshot" story different from those presented in FNC and NBA 2K16. The other key dimension is that whereas the narrative initially focuses on Devin, it increasingly spotlights Colt. While this decision sidelines the African American 
character on the narrative level, ludically, players merely control Colt for two plays in a preseason game (and make some meaningless dialog decisions as Cole). In the games in Mathis, Colt is (literally) sidelined, as players control the high school team Colt coaches. Even though the narrative shifts its focus, ludically, players never really get to be in Colt's shoes. Although the narrative may center on Colt, gameplay spotlights Devin and, in particular toward the end, the high school football team of Mathis, which is the glue that binds the local community together and hence figures as a stand-in for the town.

\section{5. (No) Illusions of Control}

However, Mathis is trapped in utopian ideas, a microcosm of a colorblind America. But colorblindness was an illusion, if not delusion. As Sarah E. Turner and Sarah Nilsen have remarked, "There is a level of comfort in the act of imagining an America where race and color do not play an active role in the lives of anyone-despite almost daily evidence to the contrary" (4). Indeed, postracial Mathis only becomes possible because past and present injustices are ignored. Devin's blackness and Colt's whiteness are never explicitly addressed, but both characters are indebted to long lines of racialized representations in audiovisual media. The same holds true for the story modes in FNC and NBA $2 k 16$, with the difference being that these two narratives do not even try to conceal their larger implications. All three narratives acknowledge that the fulfilment of the American Dream requires sacrifices but nevertheless market the Dream as a reality accessible to anyone, irrespective of race.

The story modes thus depict professional male athletes' experiences in a way that is devoid of both everyday problems and systemic obstacles. Instead of (more or less) authentic simulations of social realities, the video games offer whitewashed versions of African American athletes' lives which conform to key American myths, as the African American experience relayed through these video game modes adheres to meritocratic ideals. Notably, in none of the stories do players have much of an influence on the outcome of the story they participate in. Players are guided into a few irrelevant decisions, but the narratives unfold in a predetermined manner. ${ }^{4}$ At the risk of overstretching the verbal imagery, the story modes enslave players. Through the illusion of interaction, these video games produce what, to draw on Michel Foucault, may be termed procedural docility. The constant requirement to abide, through procedural coercion, to rules dictated by the story modes becomes emblematic of the cultural operations of national ideology. After all, docile bodies are in line with the dominant ideology (Foucault 135-69). The interactive dimension of video games adds to the effect here, as the story modes do not simply promote the myths of meritocracy and colorblindness through narrative means but rather force players to virtually perform them. However, Andre, Freq, Devin, and Colt are little more than cardboard characters that play their roles in well-known stories; and they are as trapped in their worlds as players are in theirs. 


\section{BIBLIOGRAPHY}

Baker, Aaron. Contesting Identities: Sports in American Film. U of Illinois P, 2003.

Baraka, Imamu Amiri. “Technology \& Ethos.” Raise, Race, Rays, Raze: Essays Since 1965. Random House, 1972, pp. 155-57.

Boulter, Jonathan. Parables of the Posthuman: Digital Realities, Gaming, and the Player Experience. Wayne State UP, 2015.

Boykoff, Jules, and Ben Carrington. "Sporting Dissent: Colin Kaepernick, NFL Activism, and Media Framing Contests." International Review for the Sociology of Sport, vol. 55, no. 7, 2019, 829-49.

Cernkovich, Stephen A., Peggy C. Giordano, and Jennifer L. Rudolph. "Race, Crime, and the American Dream." Journal of Research in Crime and Delinquency, vol. 37, no. 2, 2000, pp. 131-70.

Creitz, Charles. “Lawrence Jones: NBA ‘Owner’ Nix Is ‘Political Correctness Gone Wild.” FOX News, 25 June 2019, foxnews.com/sports/nba-owner-lawrence-jones-political-correctness. Accessed 25 Feb. 2020.

DeMott, Benjamin. The Trouble with Friendship: Why Americans Can't Think Straight about Race. Yale UP, 1995.

Dyer, Richard. White. Routledge, 1997.

Elson, Malte, Johannes Breuer, James D. Ivory, and Thorsten Quandt. "More Than Stories with Buttons: Narrative, Mechanics, and Context as Determinants of Player Experience in Digital Games." Journal of Communication, vol. 64, no. 3, 2014, pp. 521-42.

Fight Night Champion. Developed by EA Canada. EA Sports, 2011. Xbox 360.

"Fight Night Champion: User Reviews." Metacritic, metacritic.com/game/xbox-360/fight-nightchampion/user-reviews. Accessed 15 Feb. 2020.

flowsion. "re: Cam Newton is a fool. Wonderlic proof." SEC Rant, 9 Feb. 2016, secrant.com/rant/ sec-football/cam-newton-is-a-fool--wonderlic-proof/61834302/. Accessed 15 Feb. 2020.

Foucault, Michel. Discipline and Punish: The Birth of the Prison. Translated by Alan Sheridan, Vintage, 1995.

Fuchs, Michael, and Michael Phillips. "LeBron James and the Web of Discourse: Iconic Sports Figures and Semantic Struggles." ConFiguring America: Iconic Figures, Visuality, and the American Identity, edited by Klaus Rieser, Michael Fuchs, and Michael Phillips, Intellect Books, 2013, pp. 65-92.

Good, Owen S. “2017: The Year of Story-Driven Sports Video Games.” Polygon, 7 Dec. 2017, polygon.com/2017/12/7/16745268/game-of-the-year-goty-madden-nba2k-best-sports-games. Accessed 15 Feb. 2020.

Gray, Herman. Cultural Moves: African Americans and the Politics of Representation. U of California P, 2005.

Gray, Kishonna L. Intersectional Tech: Black Users in Digital Gaming. LSU P, 2020.

Hawkins, Billy. The New Plantation: Black Athletes, College Sports, and Predominantly White NCAA Institutions. Palgrave Macmillan, 2010. 
Hughey, Matthew W. The White Savior Film: Content, Critics, and Consumption. Temple UP, 2014. Kindle edition.

Johnson, Darrell L., Christopher J. Hallinan, and R. Carl Westerfield. "Picturing Success: Photographs and Stereotyping in Men's Collegiate Basketball." Journal of Sport Behavior, vol. 22, no. 1,1999 , pp. 45-53.

Keogh, Brendan. A Play of Bodies: How We Perceive Videogames. MIT P, 2018.

King, C. Richard, and David J. Leonard. "Why Sports Films Matter; Or, Refusing a Happy Ending." Visual Economies of/in Motion: Sport and Film, edited by C. Richard King and David J. Leonard, Peter Lang, 2006, pp. 227-38.

Kopf, Dan. “The Video Game Series ‘Football Manager' Has a Racism Problem.” Quartz, 11 June 2019, qz.com/1636057/football-manager-2019-has-a-racism-problem/. Accessed 15 Feb. 2020.

Leonard, David J. "Performing Blackness: Virtual Sports and Becoming the Other in an Era of White Supremacy." re:skin, edited by Mary Flanagan and Austin Booth, MIT P, 2007, pp. 321-39.

-----. Playing While White: Privilege and Power On and Off the Field. U of Washington P, 2017.

-----. “The Real Color of Money: Controlling Black Bodies in the NBA.” Journal of Sport \& Social Issues, vol. 30, no. 2, 2006, pp. 158-79.

Leonard, David J., and Bruce Lee Hazelwood. "The Race Denial Card: The NBA Lockout, LeBron James, and the Politics of New Racism." The Colorblind Screen: Television in Post-Racial America, edited by Sarah E. Turner and Sarah Nilsen, NYU P, 2014, pp. 108-39.

Levinson, Julie. The American Success Myth on Film. Palgrave Macmillan, 2012.

Low, Gail Ching-Liang. White Skins/Black Masks: Representation and Colonialism. Routledge, 1996.

Madden NFL 18. Developed by EA Tiburon. EA Sports, 2017. Xbox One.

Madden NFL 19. Developed by EA Tiburon. EA Sports, 2018. Xbox One.

McDonalds, Mary G., and Jessica Toglia. "Dressed for Success? The NBA's Dress Code, the Workings of Whiteness and Corporate Culture." Sport in Society, vol. 13, no. 6, 2010, pp. 970-83.

McGowan, Todd. Spike Lee. U of Illinois P, 2014.

Nakamura, Lisa. Cybertypes: Race, Ethnicity, and Identity on the Internet. Routledge, 2002.

NBA 2K16. Developed by Visual Concepts. 2K Sports, 2015. Xbox One.

"NBA 2K16: User Reviews." Metacritic, metacritic.com/game/playstation-4/nba-2k16/userreviews. Accessed 15 Feb. 2020.

Nelson, Xalavier, Jr. “Fight Night Champion Is Too Good to Stay Dead.” Polygon, 19 July 2019, www.polygon.com/2019/7/19/20699760/fight-night-champion-design-story-retro. Accessed 15 Feb. 2020.

Newitz, Annalee, and Matt Wray. "Introduction." White Trash: Race and Class in America, edited by Matt Wray and Annalee Newitz, Routledge, 1997, pp. 1-12.

Piacenza, Joanna. “The NFL Isn’t the Only Divisive Sport in America.” Morning Consult, 25 Jan. 2018, morningconsult.com/2018/01/25/nfl-isnt-divisive-sport-america/. Accessed 15 Feb. 2020.

Plaut, Victoria C. “Diversity Science: Why and How Difference Makes a Difference.” Psychological Inquiry, vol. 21, no. 2, 2010, pp. 77-99. 
Rhoden, William C. “Challenging the N.B.A.'s New Order.” The New York Times, 12 Nov. 1992. nytimes.com/1992/11/12/sports/sports-of-the-times-challenging-the-nba-s-new-order.html. Accessed 15 Feb. 2020.

-----. Forty Million Dollar Slaves: The Rise, Fall, and Redemption of the Black Athlete. Three River P, 2006.

Russworm, TreaAndrea M. "Computational Blackness: The Procedural Logics of Race, Game, and Cinema; Or, How Spike Lee's Livin' Da Dream Productively ‘Broke’ a Popular Video Game.” Black Camera: An International Film Journal, vol. 10., no. 1, 2018, pp. 193-212.

-----. “NBA 2K16: Race.” How to Play Video Games, edited by Matthew Thomas Payne and Nine B. Huntemann, NYU P, 2019, pp. 126-33.

Sheppard, Samantha N. "The Exception That Proves the Rule: Race, Place, and Meritocracy in Rand University." Black Camera: An International Film Journal, vol. 10, no. 1, 2018, pp. 162-76.

“The Shop 01." The Shop, season 1, episode 1, HBO, 29 Aug. 2018. Amazon Video, amazon.com/ The-Shop-01/dp/B07JDD1GT8/. Accessed 15 Feb. 2020.

Smith, Gillian. "A Proceduralist View on Diversity in Games." Journal of Games Criticism, vol. 3, bonus issue A, 2016. gamescriticism.org/articles/smith-3-a. Accessed 15 Feb. 2020.

Stallybrass, Peter, and Allon White. The Politics and Poetics of Transgression. Cornell UP, 1986. Terman, Lewis M. The Measurement of Intelligence: An Explanation of and a Complete Guide for the Use of the Stanford Revision and Extension of The Binet-Simon Intelligence Scale. Riverside P, 1916.

TMZSports. “Adam Silver Says NBA Office Is Done With Term 'Owner."” YouTube, uploaded by TMZSports, 24 June 2019, youtube.com/watch?v=Z24WF2kcA60. Accessed 15 Feb. 2020.

Tower, Nikole. "In an Ethnic Breakdown of Sports, NBA Takes Lead for Most Diverse." Global Sport Matters, 12 Dec. 2018. globalsportmatters.com/culture/2018/12/12/in-an-ethnic-breakdown-ofsports-nba-takes-lead-for-most-diverse/. Accessed 15 Feb. 2020.

Turner, Sarah E., and Sarah Nilsen. "Introduction." The Myth of Colorblindness: Race and Ethnicity in American Cinema, edited by Sarah E. Turner and Sarah Nilsen, Palgrave Macmillan, 2019, pp. 1-9.

Ware, Nicholas. "God-Fans and the Gridiron: Madden, Fantasy, Football, and Simulation." Football, Culture and Power, edited by David J. Leonard, Kimberly B. George, and Wade Davis, Routledge, 2017. Kindle edition.

\section{NOTES}

1. His writing and production credits include the controversial race drama Monster's Ball (2001), which won Halle Berry an Academy Award for Best Actress, the critically acclaimed cop show Southland (NBC, 2009; TNT 2010-2013), and the Civil War-era drama Copper (BBC America, 2012-2013).

2. This is another one of several narrative disconnects, as the owner praises Freq's performances on the court and celebrates his value to the team no matter how bad Freq may have played and no matter how many superstars may be on the team's roster.

3. On the purported intellectual inferiority of African American athletes, see also chapter two in David Leonard's Playing While White (2017). 
4. Of course, even if players had an influence on the narrative, that influence would be offered by the game, would have been coded into the game's architecture before the player would activate it.

\section{ABSTRACTS}

This article discusses sports video game story modes in Fight Night Champion (EA Canada, 2011), a boxing game, NBA 2K16 (Visual Concepts, 2015), a basketball game, and the story that stretches across Madden NFL 18 (EA Tiburon, 2017) and Madden NFL 19 (EA Tiburon, 2018), EA Sports' annual football series. Focusing on African American athletes, the stories tap into the utopianism of sports and suggest that anyone, irrespective of skin color, can make it in America. This article explores the racial politics of these games, in particular as experienced by a white player such as the author. Primarily focusing on narrative and gameplay, the article discusses how a white player's control over black bodies confronts them with their racial normativity.

\section{INDEX}

Keywords: blackness, whiteness, video games, sports, sports games, narrative

\section{AUTHOR}

\section{MICHAEL FUCHS}

Michael Fuchs is a postdoc in the project "Fiction Meets Science" at the University of Oldenburg in Germany. He has co-edited six books, most recently Fantastic Cities: American Urban Spaces in Science Fiction, Fantasy, and Horror (UP Mississippi, 2022) and Intermedia Games-Games Inter Media: Video Games and Intermediality (Bloomsbury, 2019), and authored and co-authored sixty-plus articles and book chapters on horror, science fiction, video games, and contemporary American literature. He is the managing editor of JAAAS: Journal of the Austrian Association for American Studies. For more information on his past and ongoing work, see www.michael-fuchs.info. 